\title{
Patterns of Absolute and Relative Social Mobility: a Comparative Study of England, Wales and Scotland
}

\author{
by Lindsay Paterson and Cristina lannelli \\ University of Edinburgh
}

\author{
Sociological Research Online 12(6)15 \\ <http://www. socresonline.org.uk/12/6/15.html> \\ doi:10.5153/sro. 1637
}

Received: 29 Jun 2007 Accepted: 15 Oct 2007 Published: 30 Nov 2007

\begin{abstract}
We use the British Household Panel Study to analyse change over birth cohorts in patterns of social mobility in England, Scotland and Wales. In several respects, our conclusions are similar to those reached by other authors on the basis of wider comparisons. There has been a large growth in non-manual employment since the middle of the twentieth century. This led first to a rise in upward mobility, but, as parents of younger people have now themselves benefited from that, has more recently forced people downward from their middle-class origins. These changes have largely not been a growth in relative social mobility: it is change induced by the occupational structure. The conclusions apply both to current class and to the class which people entered when they first entered the labour market. The patterns of relative mobility could not be explained statistically by measures of the respondents' educational attainment. The conclusions were broadly the same for the three countries, but there was some evidence that in the youngest cohort (people born between 1967 and 1976) experience of people from Wales was diverging from that of people from England and Scotland, with rather greater amounts of downward mobility. There were two methodological conclusions. Out-migration from country of birth within the UK did not seem to make any important difference to our results. That is encouraging for analysis of surveys confined to one of the three countries, because it suggests that losing track of out-migrants would not distort the results. The second methodological conclusion is that the comparative study of social mobility can find interesting topics to investigate at social levels lower than that of the state, here the comparison of the three countries which make up Britain.
\end{abstract}

\section{Keywords: Social Mobility; Comparative Research; British Household Panel Study; Loglinear Modelling}

\section{Introduction}

1.1 There are six broad conclusions from research since the 1970s on comparative social mobility:

- The over-riding conclusion is that there continue to be high and converging absolute levels of mobility in all developed societies: it is normal for people to occupy a different class to that in which they were brought up (Breen and Luijkx, 2004, pp. 48 and 66; Breen and Whelan, 1999; Goldthorpe, 1987; Marshall et al., 1988; Marshall et al., 1997; Payne, 1987; Saunders, 1995; Savage, 2000).

- Nevertheless, the extent to which social fluidity has changed varies between countries (Erikson and Goldthorpe, 1992; Marshall et al., 1997, pp. 37-69). That is, as between different classes of origin, the relative chances of being in one destination class rather than another has changed more in some countries than others. For example, the contributions to the book edited by Breen $(2004 a, b)$ and summarised by Breen and Luijkx (2004a) found that between the 1970s and the 1980s there were significant increases in fluidity in France, Ireland, Sweden, Poland, Hungary and the Netherlands, but that between the 1980s and the 1990s further increases took place only in the Netherlands. Britain and Germany had stable fluidity throughout this period.

- These first two questions indicate the importance of looking at both absolute and relative mobility. The main disagreements in the debate are essentially over whether the high levels of absolute mobility tell us anything very interesting about opportunity. Despite the cogency of the argument by, for example, Ringen (1997, pp. 129-48), Hellevik (1997), Noble (2000) and Payne and Roberts (2002) that absolute mobility merits serious attention, we are convinced by, for example, Swift (2000), 
Marshall and Swift $(1993,1999)$ and Swift and Marshall (1997) that understanding social fluidity is an important aspect of investigating social inequality and social justice, and hence that relative rates have to form the core of any investigation.

- However, it is important to understand also how the high and changing absolute rates may be reconciled with unchanging relative rates. This may be done by means of the further evidence (from these same studies) that the main influence on mobility chances has been the overall shape of the occupational distribution. Thus, because the service class has expanded, and the manual working classes have contracted, to a point where many developed societies may be described as 'postindustrial', most people interviewed in surveys in the late- $20^{\text {th }}$ century were bound to be found in a different class from that of their parents. So when we use the unqualified term 'social mobility', we are referring to both absolute and relative mobility. Where the distinction is important, we make it explicitly.

- Although most of these processes have resulted in some convergence of absolute mobility among nations (Breen and Luijkx, 2004a) - mainly because of the rapid decline of agricultural employment in those European countries where this sector was still large in the middle of the 20th century and also because of the growth of the service class - the convergence is not complete; modernisation has not entailed the uniformity that was expected by earlier theorists of liberalism (For this debate see Breen and Whelan, 1994; Marshall et al., 1997, pp. 38 and 44; Parsons in Grusky, 1994;

Treiman, 1970; Whelan, 2004). In particular, levels of social fluidity vary between countries.

- There is variation among countries in the extent to which the changing distribution of educational attainment explains any changes in the association of origins and destinations: although social mobility may be increasingly mediated by education, as Halsey argued a quarter of a century ago (Halsey, 1977), that leaves scope for a great deal of variation among countries in the extent of the mediation for any particular cohort (Breen and Luijkx, 2004a,b).

1.2 The countries of Britain have participated in these social processes as thoroughly as any, and have been included in most of the main comparative studies of social mobility since the 1970s. Within Britain, moreover, the occupational and mobility patterns of Scotland on the one hand and England and Wales on the other have been converging for much longer than the recent mobility studies indicate as the period of greatest convergence more widely (McCrone, 1992, pp. 55-87). Indeed, the striking feature of the economies of Scotland and of England is how similar they have been in employment structures since at least the early part of the $20^{\text {th }}$ century.

1.3 Internal comparisons of this kind within Britain have not been carried out in the most recent waves of mobility studies, in contrast to those in the 1970s. The rationale for investigating comparative questions by means of the separate national societies of the UK has been discussed fully by Raffe et al. (1999): one advantage is that, because the broad patterns of social class and the nature of the economy are much the same throughout the UK, we are better able to test whether there is any scope for variations in social fluidity or in absolute levels of mobility in otherwise common social structures. This research design is sometimes referred to in political science as using 'most similar comparisons': see, for example, Przeworski and Teune (1970, pp. 32-4). We ask in this paper whether the patterns of difference or convergence that arise between three closely connected societies may be explained in similar terms to those that have been useful in studying societies that are governed by separate states. This paper uses synthetic cohorts constructed from the British Household Panel Study to investigate the extent to which the largely common employment history of England, Wales and Scotland has led to these countries' sharing in the reported international experience of social mobility. As described in more detail in the Appendix, the BHPS was inaugurated in 1991 to track individual change over time. It is useful for our purposes because it collected rich information about respondents' life histories before that point, and also because, in 1999, the sample was increased in Wales and in Scotland therefore allowing reliable comparisons among the three countries of Britain. Thus, unlike most previous comparisons internal to Britain, we are able to study Wales separately from England.

\section{Data and Methods}

2.1 The surveys are described in the Appendix. Seven main variables are used. Place of birth has simply been categorised as England, Wales and Scotland, and (apart from in Table 16) respondents who were not born in these three countries have henceforth been omitted. The purpose of this restriction is essentially for reasons of research design: by means of it, we do not confuse our inferences by the quite different mobility experience of recent immigrants (Platt, 2005). We return to discuss this point at the end. We refer to the retained sample as the 'British' sample. It contained 14,141 cases (of all ages 15 and over); this number falls further once we have omitted people with missing data and restricted the age range as noted below. The variable recording place of birth is referred to as ' $\mathrm{B}$ '. We also use the gender of respondents, although - as reported later - we conclude that the patterns of social mobility in which we are primarily interested did not vary by gender. The five other variables were:

\section{Birth cohort: variable ' $C$ '}

2.2 Any division into decades is arbitrary, but we use the categories 1937-46, 1947-56, 1957-66 and 196776; the rationale for this choice is summarised by Paterson and lannelli (2007, Table 1). We confine ourselves to people born after the mid-1930s because the level of missing data on class of origin and current class rises sharply for older ages. We also include only people aged 23 and older in 1999, because most of them would have entered the labour market by then. The resulting sample consisted of 9,510 cases, 6,001 born in England, 1,492 born in Wales and 2,017 born in Scotland. In later tables, these numbers fall further because of the exclusion of missing data on class variables.

2.3 Any analysis based on synthetic cohorts of this sort is liable to bias due to differential mortality or 
differential levels of migration out of the country of birth (Heath and Payne, 1999; Noble, 2000; Payne and Roberts, 2002). We consider this question of out-migration in more detail later, but our conclusion is that, while we cannot be sure that there is no bias, the likely effect is small. We have guarded against the greatest threat to bias from migration by defining the spatial variable as where people were born rather than as where they were living at the time the survey was carried out; but we also discuss in the final section the possible effects of migration more generally (thus embracing also in-migration and return migration). We also replicate the main analysis on sub-samples restricted to people who were living in the same country as that in which they were born.

\section{Class of origin: variable ' $\mathrm{O}$ '}

2.4 This was derived from the information on fathers' and mothers' occupation when the respondent was aged 14. We follow the main literature in this area by using the Goldthorpe class scheme (Breen, 2001; Erikson and Goldthorpe, 1992, pp. 38-9; Marshall et al., 1997, pp. 21-35), condensed as exemplified in Table 1. Respondents were assigned to the class of the parent who had the higher status on the Goldthorpe scheme (the 'dominance rule'). The unweighted proportion of the British sample aged 23-62 allocated to an origin class from father's class was $56 \%$, from mother's class was $22 \%$, and from both equally was $11 \%$; the remaining $11 \%$ had no information on either parent's class; the proportion with mother's class dominant varied across the four cohorts, being respectively $14 \%, 20 \%, 25 \%$ and $29 \%$.

\section{Destination class: variables ' $D$ ' and 'D1'}

2.5 We measure destination class in two ways. The main one is based on the respondent's occupation in 1999, again coded into the Goldthorpe scheme as shown in Table 1. Note that the reason we have retained six categories is the expansion of the service class mentioned in the Introduction: with more than one in six people in the upper service class, it becomes important to distinguish between it and the lower service class, including movement between these classes as mobility. The importance of doing this is not only numerical: it also relates to distinctions of status and power that are internal to the salariat, and which the growth of that class makes more evident. We will be referring to movement 'up' and 'down' the six-point scale. The main presuppositions in this terminology are that occupations further up the hierarchy confer greater security, higher pay, more autonomy and better opportunities for promotion than those further down. Evidence in broad support of these is provided by Evans (1992) and Evans and Mills (2000). Doubt has sometimes been raised about the place of Goldthorpe's class IIIb (lower-grade routine non-manual) in this hierarchy, and so we also re-calculated the mobility proportions after grouping this class with the unskilled class VII; comment on the results is included along with discussion of Tables 3 and 6 . Nevertheless, there is no strong reason from the work of Evans and Mills to prefer this re-grouping to the one we have mainly used. The technical aspects of our statistical models (described below) do not depend on any assumptions about the ordering of the classes.

2.6 The measure records part-time as well as full-time occupations. Where respondent's class was missing, it has been imputed where possible as the class of the highest-class person in the household where the respondent was living in 1999. The unweighted proportion of the British sample aged 23-62 allocated from own class was $74 \%$, and from someone else in the household was $12 \%$; the remaining $15 \%$ remained without a current class. There was a small gender difference in these proportions: $16 \%$ of women had class imputed from someone else in the household. However, the conclusions seemed rather impervious to this imputation: the main models below (as reported in Tables 4 and 7 ) were re-run excluding the whole $27 \%$ who could not be allocated from their own class, and the results were very similar. We refer to this as 'current class', and denote it by 'D'.

2.7 We also have information on the respondent's 'first job after leaving full-time education'. This question was asked in two ways in the BHPS. For the whole main sample (as started in 1991), it was collected in wave three as part of a comprehensive account of respondents' employment history. For new respondents from wave eight onwards (thus including the whole extension samples in Wales and Scotland) it was asked in the main baseline questionnaire. We have used these two sources to construct a measure of first job for every respondent who answered one or other version. We refer to this as 'initial class', and denote it by ' $\mathrm{D}_{1}$ '. Analysing initial class as well as current class allows us to overcome some of the conceptual problems of using synthetic cohorts (Payne and Roberts, 2002, para. 2.8): it standardises on a particular point in the occupational cycle, which is unaffected by the different ages of the cohorts at the time of the survey (except insofar as the reliability of respondents' memory or their willingness to report it accurately varies with age). In this sense, we have a measure that standardises approximately for stage in a career. However, because we do not have longitudinal data, we cannot standardise for period and age at the same time: our analysis has to choose between examining people either at the same stage of a career (through first job) or at the same point in time (current job). Comparing the two kinds of analysis will give some indication of whether mobility within a career makes a difference to the extent and patterns of mobility from childhood to adulthood.

\section{Educational attainment: variable 'E'}

2.8 The relationship between class of origin and the gaining of educational certificates is analysed more fully by lannelli and Paterson (2007) and Paterson and lannelli (2007). We use this variable here for the sole purpose of testing whether the changing distribution of attainment may explain any changes in the association of origins and destinations. The attainment variable has six categories: no certificates, certificates at levels lower than lower secondary schooling, certificates at the level of lower secondary schooling, certificates at the level of upper secondary schooling, certificates at higher education level below degree, and degrees. 


\section{Analysis}

2.9 Thus we are primarily interested in the associations between the variable $O$ and $D$, and any interaction of these with the variables $B$ and $C$. We test this by log-linear modelling, using the software LEM developed by Jeroen Vermunt of the University of Tilburg (Vermunt, 1997). The general approach to loglinear modelling which we use is outlined by, for example, Erikson and Goldthorpe (1992, pp. 28-64) and Payne et al. (1994). In our notation, single variables refer to main effects, for example $O$ to the main effect of class of origin. Concatenations of variables refer to interactions: for example, OD refers to the interaction of origin and current classes. Thus, unlike some authors, we do not use 'OD' to include the main effects, and we would always write the saturated model for the OxD table as $O+D+O D$. The fit of models is measured in the usual way by the $\mathrm{L}^{2}$ statistic, which is the same as the log likelihood ratio and thus is (under the relevant null hypothesis) approximately distributed as a chi-squared statistic. In descriptive tables, we also use the dissimilarity index. For example, in each segment of Table 1, it is calculated as one half of the sum of the absolute differences between the percentage in the 'origin' column and the percentage in the 'destination' column. The dissimilarity index is a widely used descriptive measure of the extent to which two distributions do not resemble each other: it may be thought of as the proportion of either distribution that would have to change category for the two distributions to be identical.

\subsection{The statistical models in which we are mainly interested are as follows:}

- (1) Are there any national differences in the extent to which class of origin is associated with current class? This is assessed by testing whether there is a need for an ODB interaction in the OxDxB table.

- (2) If we do not find any such national differences, do any become evident if we remove the extent to which the distribution of destinations varies among the three countries? Removing control for variation in the distribution of destinations means dropping the interaction DB. We use DB here to reflect changes in the occupational structure because it is directly relevant to describing the impact of occupational change on our respondents. OB would also reflect occupational change, but lagged by one generation. So the question is: does adding the ODB interaction make any difference to the model $O+D+B+O D+O B$ ? Note that the resulting models will be non-hierarchical because ODB is included but DB is not. The model with DB included may be thought of as estimating what ODB would be if the distribution of destinations were (counterfactually) the same in the three countries for example, discounting the effects of there being a proportionately larger professional class in one nation than in another. The model without DB therefore estimates ODB when the distribution of destinations varies among the countries in the manner observed in the data. This is the modelling equivalent of being interested in variation among the whole set of 18 origin classes (six in each of three nations). The variation which the interactive effect ODB measures in this non-hierarchical model includes, for instance, variation which places the proportion entering the professional class from the lowest origin class in one nation $\mathrm{N}$ above some higher origin classes within another nation $\mathrm{M}$, not because inequality is lower in $\mathrm{N}$ but because the professional destination class in $\mathrm{N}$ forms a larger share of the destination class structure than in $\mathrm{M}$.

- (3) Does the association of origin and destination vary over time? This will assess whether social mobility has changed over time. We test it first by calculating whether the interaction ODC adds anything to the model $O+D+C+O D+O C+D C$, and then - analogously to (2) - after removing the term DC.

- (4) Where we do find an ODC interaction, we also summarise it more concisely by the so-called 'unidiff' model (Erikson and Goldthorpe, 1992, pp. 91-2; Payne et al, 1994, pp. 67-9). The full threeway interaction ODC may be thought of as fitting OD separately for each cohort, thus in each cohort yielding a completely different set of the OD parameters. A unidiff (or 'uniform difference') model simply constrains the ways in which these parameters may vary: they vary between cohorts only by a constant scaling factor that operates multiplicatively on the logarithmic scale on which the parameters in a log-linear model are estimated. The unidiff parameters thus represent strengthening or weakening of the association between $\mathrm{O}$ and $\mathrm{D}$, relative to a baseline which we will set to be the oldest cohort: a value of the unidiff parameter greater than 1 indicates a strengthening, a value less than 1 a weakening. Thus these scaling factors give a succinct measure of any trends in the strength of the O-by-D association: the higher the factor, the stronger the association.

- (5) Does any ODC interaction vary among the countries? This will test whether there has been convergence in the mobility patterns among the three countries. The first way of testing this is whether the interaction ODCB adds anything to a baseline model that contains all the main effects, all the 2-way interactions, and all the 3-way interactions.

- (6) Analogously to (2), does the answer to (5) change if we remove from the baseline model against which ODCB is compared all terms that might reflect different current occupational structures in the three countries and different trajectories in these over time? That is, from the baseline model summarised in (5), we remove the interactions DB (different structures), DC (changing structures over time) and DCB (differences among countries in any changes in the occupational structure over time).

- (7) Finally, we repeat all these steps for initial class rather than current class.

2.11 For further discussion of this approach to understanding higher-order interactions such as ODB, see Paterson and lannelli (2007). It is analogous to that outlined theoretically by Ringen (1997, pp. 129-48) and Swift (2000) and developed by Ringen and by Breen (2004). However, as we noted in the introduction, we are not suggesting that measures of association are not useful. Our models that omit certain margins (such as (2), (3) and (6)) are offered not as alternatives to standard hierarchical log-linear models but as ways of explaining why, in them, apparent social fluidity might not be detectable. 


\section{Current class}

3.1 Table 1 shows the classes of origin and destination by country of birth. The main point to note is the extent to which the countries resemble each other: for example, on origins, $42-46 \%$ are in the manual class, a proportion that drops in each country to 30-33\% among destinations. The resemblance extends, in particular, to the expanding professional classes: the proportions are $27-30 \%$ for origins and $38-40 \%$ for destinations. The dissimilarity indexes in that table do show that there is greater disparity between origins and destinations among people born in Scotland and England than among those born in Wales. The dissimilarity indexes in the rows labelled 'all' in Table 2 confirm that Wales is somewhat different: its dissimilarity index on origins is 6 in the comparison with England and 8 in the comparison with Scotland, greater than the 4 comparing Scotland and England. Although (as reflected in the comparison of origins with destinations) Scotland and England may have grown closer together, there is no evidence that Wales has converged with either: for current class, the differences of Wales from England (8) and Scotland (10) are even greater than for origins, whereas that between Scotland and England is only 3. From Table 1 we also see that the proportions of destinations in the routine non-manual class and in the lower-grade professional class were lower for Wales than for England and Scotland (for each of these classes, around $18 \%$ compared to around $22 \%$ ). Table 3 , however, further shows that the overall amount of mobility is very similar in each country: from each, around $45-46 \%$ have been upwardly mobile, around $23-24 \%$ have been immobile, and around $31-32 \%$ have been mobile downward. These proportions barely changed when (as described above) the lower-grade routine non-manual class IIIb was grouped with the unskilled class VII.

3.2 The broad similarity of the mobility patterns in each country is confirmed by the modelling summarised in Table 4. The model 1 which contains all three main effects and all three 2-way interactions provides a satisfactory fit to the data, and so there is no need for the 3-way interaction ODB that would indicate country differences in the extent of relative mobility. However, the importance of the differences which were evident from Tables 1 and 2 is shown in the next pair of models, which do not contain the interaction DB: now there is some evidence of an ODB interaction. In other words, the different destination distributions (DB) have induced different patterns of mobility. The relative mobility chances do not vary among the countries (model 1); but more people in Wales than in England or Scotland moved downward from origins in the middling classes: the total downward mobility from the lower professional class was $57 \%$ in Wales, $50 \%$ in England and $47 \%$ in Scotland, and from the intermediate non-manual class was $40 \%$ in Wales, $36 \%$ in England and $32 \%$ in Scotland. We would emphasis that we are not suggesting that model 3 is a better way of representing the data than model 1 : in fact, judging by the values of $L^{2}$ in relation to the number of degrees of freedom, model 3 fits the data less well than model 1 . The purpose of model 3 is to help us understand how model 1 , showing no country differences in inequality, is consistent with the apparent such differences in Tables 1 and 2.

3.3 Controlling for the different distributions of educational attainment in the three countries makes almost no difference to this conclusion. We did this by fitting models analogous to models 2 and 3 in Table 4 , but allowing all the terms in the baseline model 2 to interact with the attainment variable $E$. Thus model 2 was augmented by the terms E, OE, DE, BE, ODE and OBE. Then, as in Table 4, the interaction ODB was added. The change in $\mathrm{L}^{2}$ was 63.0 , still on 50 degrees of freedom, similar to that in Table 4.

3.4 These comparisons of origins and destinations all imply a need to investigate changes over time. The descriptive summary data are in Table 5 , which shows origins and destinations by birth cohort and country of birth. For each country, the growth in non-manual employment (the first four class categories) is clear by comparing the destinations of the youngest cohort with the origins of the oldest: for England, $68 \%$ against $42 \%$; for Wales, $57 \%$ against $46 \%$; for Scotland $68 \%$ against $44 \%$. The dissimilarity indexes in that table, comparing origins and destinations, show clear falls over time. The result, as shown in Table 6 , is that, although total mobility has not changed much, there has been a shift towards downward mobility away from upward, as more people in the younger cohorts than in the older start in middle-class families.

Nevertheless, that change has been less marked among people born in Wales than in England and Scotland. (Again, these proportions barely changed when the lower-grade routine non-manual class IIIb was grouped with the unskilled class VII.) Furthermore, the dissimilarity indexes in Table 2 show that, whereas the experience of people born in all three countries was converging in the middle cohorts, those born in Wales started to diverge again in the youngest, whereas those born in Scotland and England grew closer together.

3.5 The formal tests of these points are in the sequence of models in Table 7. The first pair shows hierarchical log-linear models assessing whether there is a need for an ODC interaction; the conclusion is that there is not. That is, there is no evidence that (averaged over countries of origin) the relative mobility chances change over cohorts. (We return to model 3 shortly.) The pair of models 4 and 5 then do the same as models 1 and 2, but without the terms DB and DC; now we conclude that there is evidence of an ODC interaction. These two omitted terms measure the extent to which the current occupational structure differs among countries of origin or among cohorts. So the conclusion from models 4 and 5 is that the variations in current occupational structure have induced variations over cohort in social mobility; the contrast with the conclusion from models 1 and 2 indicates that that variation over cohort is entirely driven by changing occupational structure, and cannot be attributed to changing relative chances of mobility. Put differently, the changing patterns of mobility shown in Table 6 are due to changes in the opportunities available to people who were born at different times.

3.6 As with Table 4, moreover, controlling for educational attainment did not lead us to modify this conclusion. This was done by adding to the baseline model 4 in Table 7 the interaction of each of its terms with variable $\mathrm{E}$. The interaction ODC was then added, as for model 5 in Table 7 ; the reduction in $\mathrm{L}^{2}$ was 
204.5, still on 75 degrees of freedom. There was certainly no evidence, then, that the ODC interaction could be explained by changes in the distribution of attainment. The reason is illustrated in Table 8, which shows the proportion who have been upwardly mobile in each cohort according to their broad level of attainment (grouping together the two lowest levels to give reasonable sample sizes): there is very little variation in mobility that could be attributed to education, and even less variation in that respect over time.

3.7 Models 6 and 7 in Table 7 then show, further, that there is some evidence of differences among countries in the variation of social mobility over cohorts (that is, the ODC interaction varies by country of origin), if the interactions DB and DC and their interaction DBC are excluded. Note that a similar conclusion would also have been reached from model 3, which fits all the interactions with three terms or fewer: that model still leaves unexplained variation (189.5 on 150 degrees of freedom). This conclusion from model 3 is forced on us even though the comparison between models 1 and 2 would have led us to believe that there was no variation in social mobility over cohorts.

3.8 The nature of these changes in patterns of mobility may be clarified by the results of a 'unidiff' model (as explained in point (4) in the discussion of methods earlier). This substitutes for the full ODC interaction a simplified structure in which the O-by-D association varies only by a log-multiplicative scaling factor over cohorts. The resulting $L^{2}$ value was 480.2 , on 332 degrees of freedom. This is an improvement over model 4 (change in $L^{2}$ of 45.3 on 28 degrees of freedom), but it is not as good as the full ODC interaction contained in model 5 (difference of 101.9 on 47 degrees of freedom). So this log-multiplicative model does not capture all the change in OD that is present in model 5; nevertheless, it captures some of the changes, and so might point us towards patterns in the data that are responsible for them. The key part of a unidiff model is the log-multiplicative parameters. The estimates of these rose from the reference value of 1 in the oldest cohort to 1.15 in the second-oldest, and then fell to 0.88 and 0.84 in the remaining two. That is, the association between origins and destinations strengthened between the first and the second cohort, and then fell to a level below that of the first cohort.

3.9 Consider, in illustration of this, the effect of the contraction of manual employment, which for the purposes of this example we take to be the two lowest classes in the Goldthorpe scheme. The second cohort - people entering the labour market roughly in the 1960s - showed a tighter association of origin and destination because the growth in their parents' non-manual employment had not yet outstripped their own opportunities for non-manual employment: in England, the proportion of people of non-manual origin who were in non-manual jobs was $81 \%$ in both these cohorts; in Scotland it rose from $72 \%$ to $81 \%$; and, although it dropped in Wales from the very high $89 \%$ in the first cohort, it remained quite high at $70 \%$. But, by the third and fourth cohorts, the non-manual opportunities for parents had grown more rapidly than the non-manual opportunities for respondents, and so these new positions could be filled only by a partial reduction in the association with parents' class. Thus the proportion of people of non-manual origins who were in non-manual jobs had dropped to $75 \%$ in England (from a high of $81 \%$ ), to $71 \%$ in Scotland (also from a high of $81 \%$ ) and to $61 \%$ in Wales (from a high of $89 \%$ ). Indeed, by the youngest cohort, the parents would themselves have been in competition with the next generation for such jobs: the proportions of respondents in non-manual employment in Table 5 were almost the same as amongst their parents.

3.10 All of the models shown in Tables 4 and 7 were run separately for men and women, and the patterns were very similar. We also re-ran the models in Tables 4 and 7 for people who were living in the same country as that in which they were born (6611 people out of the 7330 used for these tables). The pattern of results was almost the same as shown in the tables. In particular, as from models 2 and 3 in Table 4, there was evidence that the association of origins and destinations varied among countries (an ODB interaction) when the DB term measuring the class structure in the different countries was not in the model. Likewise, there was evidence that the association of origins and destinations varied across cohorts (an ODC interaction) when DB and also the DC term measuring changes in the class structure over cohorts were not in the model (as from models 4 and 5 in Table 7). And there was evidence of differences between countries in this variation in the association of origins and destinations across cohorts (an ODCB interaction), analogous to that found between models 6 and 7 in Table 7.

\section{Initial class}

3.11 Examining the class which people occupied when they first entered the labour market allows us to understand further the ways in which these patterns of social mobility have come about. Table 9 is analogous to Table 1; there is much greater dissimilarity between origin and initial class than between origin and current class, especially at the top end of the class distribution. The dissimilarity indexes comparing countries of origin in Table 10 are analogous to those in Table 2. (Note that the comparisons of origin class are not identical to those in Table 2 because the pattern of missing data on initial class was not the same as the pattern of missing data on current class, so that the cases omitted from Table 10 are different from those omitted from Table 2.) On the whole, the countries are closer on initial class than on current class, but the divergence of Wales from England and Scotland across cohorts is found for initial class almost as strongly as for current class. Table 11 in comparison to Table 3 shows that upward mobility at initial class was less, and downward mobility greater, than at current class, which is to be expected. The models in Table 12 then show similar kinds of evidence for differences among the countries in social mobility at initial class as at current class. This conclusion was unaffected when we added a control for educational attainment in the same way as we did for Table 4: the reduction in $L^{2}$ associated with $O D_{1} B$ was then 77.4 , very close to the 78.0 in Table 12.

3.12 The variation across cohorts is shown in Table 13. The dissimilarity indexes comparing the distributions of origin and initial class vary less across cohorts than the analogous indexes did for current class in Table 5, and - at least for cohorts after the oldest (people born after the mid-1940s) - there is little 
evidence of any trend towards greater similarity between origin and initial destination. The dissimilarity indexes comparing countries, in Table 10, show that, as with current class, Scotland and England are closer together on both origins and destinations than either is to Wales.

3.13 The reduction in upward mobility and increase in downward mobility are much sharper for initial class (Table 14) than for current class (Table 6). The explanation is similar to the discussion at the end of the section on current class. For initial class, and from the third cohort onwards in each country, the proportion of parents in non-manual classes outstripped the proportion of children in non-manual classes; in the youngest cohort the gap in all three was large: from Table 13, 70\% (origin class) compared to $49 \%$ (initial class) in England, $58 \%$ compared to $45 \%$ in Wales, and $64 \%$ compared to $51 \%$ in Scotland; the gap is proportionately even starker at the top end of the class distribution. In such circumstances, substantial downward mobility was as inevitable as large amounts of upward mobility were earlier in the century when non-manual employment was expanding for cohorts whose parents were mostly working class.

3.14 The final comparison between initial and current class concerns the models in Table 15, analogous to those in Table 7. As with current class, there is evidence of change over time in the association of origins and initial class when the model does not include the 2-way interactions reflecting the changes in destinations over time $\left(D_{1} C\right)$ and the variation in destinations among countries $\left(D_{1} B\right)$ : see the comparison of models 4 and 5 in Table 15 (a reduction in $L^{2}$ of 146.9 on 75 degrees of freedom), and compare that with the very similar comparison between models 4 and 5 in Table 7 (147.2 on 75 degrees of freedom).

Controlling for education (as in our modification to Table 7) did not weaken this conclusions: the change in $\mathrm{L}^{2}$ for $\mathrm{OD}_{1} \mathrm{C}$ was if anything stronger, at 221.0 instead of 146.9. There was no evidence for initial class that the interaction of origin, destination and cohort varies among countries: see the comparison of models 6 and 7 in Table 15.

3.15 Taking these results with the conclusions on current class raises the possibility that the changes over time in the association between origins and current class (OD), or its variation among countries, happen before people first enter the labour market. One reason to be interested in this derives from the question of whether the influence of origin on destination is exerted early in people's occupational careers, or whether mobility during a career continues to be influenced by origins. Our question is then whether any mediating effect of initial class explains later variation among countries in the association of origin and destination. In fact, there is no more than weak evidence of this. For the variation in the association between origin and destination (OD) among countries (the ODB interaction), we may incorporate initial class in the models 2 and 3 in Table 4 of current class in the same way as we included education earlier. Thus the question is whether there continues to be evidence of an ODB interaction when $\mathrm{D}_{1}$ is included in this way. The answer is that, although the reduction in $\mathrm{L}^{2}$ associated with this interaction falls, the change is relatively slight from 69.9 in Table 4 to 60.7 (both on 50 degrees of freedom, respective p-values thus being 0.03 and 0.14 ). Thus the processes that lead to differences among the three countries must be operating in the labour market throughout people's careers, not only at the point of entry.

3.16 For the variation in OD over cohorts, we may do the same to a pair of models analogous to models 4 and 5 in Table 7; the approach is again analogous to including education. The reduction in $L^{2}$ associated with ODC is, with $D_{1}$ included, 132.7 , not much less than the 147.2 in the comparison of models 4 and 5 in Table 7.

3.17 In summary of these conclusions, we can say that education does not explain any of the variation in $\mathrm{OD}$ or $\mathrm{OD}_{1}$ that we have been looking at - whether the variation across countries (ODB and $\left.O D_{1} \mathrm{~B}\right)$ or the variation across cohorts $\left(\mathrm{ODC}\right.$ and $\left.\mathrm{OD}_{1} \mathrm{C}\right)$. Furthermore, initial class does not explain any of that variation in OD.

3.18 Once more, gender made no difference to these conclusions: the patterns shown by the models in Tables 12 and 15 were very similar for men and women. Restricting attention to people who were living in the same country as that in which they were born likewise made no difference.

\section{Effects of differential mortality and out-migration}

4.1 Using a cross-sectional survey to study social change is the only option we have in the absence of regularly repeated surveys over a long period of time. The main threats to validity are selective mortality and selective migration out of the country of birth, especially with respect to social class. If we imagine for the moment a 2-by-2 table defined by a dichotomous origin class and a dichotomous destination class, each 'working class' versus 'middle class', then we might expect that the longevity would be greatest among the stable middle class, lowest among the stable working class, and probably second highest among the upwardly mobile. (Indirect support for this may be inferred from, for example, Blane et al. (1999, p. 175), who show mean height varying in just this way, and note ( $p .180)$ that height is a good indicator of later health.) That means that in the oldest cohorts we will almost certainly be over-estimating upward mobility and under-estimating downward mobility. So, in our conclusions, we may be exaggerating the fall in upward mobility, and the increase in downward mobility, across cohorts. However, since we found, on the whole, that the greatest changes of this type (in Table 6) were between the two youngest cohorts - the oldest of whom were aged only 42 in 1999 - it might be reasonable to conclude that the broad pattern of our findings has not been too distorted by differential mortality.

4.2 On out-migration, we can use the BHPS itself to look at out-migration among the four countries within the UK. The data are in Table 16; unlike all the other tables, it refers to the whole of the UK. It shows the percentage of people living in 1999 in a different country of the UK from that in which they were born, classified by whether they had been socially mobile. The main point to note is that there is little variation 
with respect to social mobility: for example, the average proportions who had migrated were $7 \%$ among the downwardly mobile, $5 \%$ among the immobile and 6\% among the upwardly mobile. There might be a slight bias in the two oldest cohorts, but even there it is not great. Detailed inspection of the origin-by-destination table showed that the highest levels of out-migration are among those whose origin is in the higher-grade professional class. If this pattern applies to migration out of Britain, then our analysis will have underestimated downward mobility and probably also immobility, especially in older cohorts. As with differential mortality, therefore, this would tend to bias our methods towards exaggerating the rise in downward mobility, but perhaps again not for the two younger cohorts.

4.3 It should be emphasised again that the actual patterns of internal out-migration shown in Table 16 do not themselves bias our results, because we have used place of birth as our spatial variable, and have also re-run our models for people who were living in the same country as that in which they were born. The sole purpose of constructing Table 16 is to estimate the association between out-migration and social mobility with a view to reflecting on any possible effects of migration out of Britain. Thus, for this to be relevant to our study, it has to be postulated that out-migration of that type follows broadly the same patterns with respect to social mobility as out-migration among countries within the UK.

\section{Conclusions}

5.1 In several ways, this comparison of the experience of people born in England, Wales and Scotland leads us to similar conclusions to those reached by other authors on the basis of wider comparisons. There has been a large growth in non-manual employment, due to a decline in the size of the manufacturing sector, to a growth in the size of the service sector, and to the upgrading of occupations in all sectors, usually requiring more skills (Gallie, 2000, pp. 285-90; Paterson et al, 2004). These changes have affected the destinations of the sample members most obviously, but, for younger cohorts, have also influenced the distribution of origin classes. Recently, therefore, there has been a growth in downward mobility, as more people are forced downward from their middle-class origins, but that is largely not a growth in what Erikson and Goldthorpe call 'social fluidity': it is change induced by the occupational structure, not by the relative chances of ending up in certain destinations (and avoiding others) having started at specified points. Distinguishing between absolute and relative mobility therefore remains important (Noble, 2000; Payne and Roberts, 2002): absolute mobility tells us about the actual changing experience of people, while relative mobility tells us about the inequalities of opportunity available to those from different classes.

5.2 The similarities of these three countries may be developed in more detail. They each show similar convergence of their origin and destination distributions over time (or at least across birth cohorts), and they each show similar amounts of downward and of upward mobility within each cohort. Thus the apparent changes in mobility over time are also similar. Moreover, none of these conclusions may be explained by changing patterns of educational attainment: our analysis would thus endorse the conclusion reached by Breen and Luijkx (2004b, p. 394) that the overall extent to which education mediates the impact of origins on destinations' is relatively weak in Britain. We would emphasise, nevertheless, that education is important (and see also lannelli and Paterson (2007)). It was still a means by which mobility came about, and inequalities in attainment of high levels of education remained part of the reason why origin and destination continue to be associated. The point is simply that education is not the only explanation of that association, as Table 8 showed. The fall in upward mobility in younger cohorts happened at all levels of education, because, for each origin class, new places in the next class up were not expanding rapidly enough to continue to accommodate as much upward movement as happened in the older cohorts.

5.3 Both the earlier expansion of upward mobility, and its more recent contraction, affected men and women equally. That is partly because of that component of mobility that is due to education: once women could gain access to credentials, the scope for their being selected by measured merit came to be similar to that for men. To the extent that opportunities are not mediated by education, the similarity of the mobility experience of men and women suggests that women are able to draw upon parental support in similar ways to men. For example, if the children of the service class gain good jobs partly through the skill of their parents in adding to their measured cultural capital, then that seems to be happening equally for women and men. It is tempting to speculate that one reason for this might be the growing number of households where the higher-status member is the mother: as we noted, this was true of $29 \%$ in the youngest cohort compared to $14 \%$ in the oldest, and, when families where the mother and father were of equal status are considered, fully $40 \%$ of the youngest cohort (compared to $23 \%$ of the oldest) had mothers who would have had at least as strong access to work-related networks as the fathers. This might then give young women the kinds of social capital that aids entry to employment which previously men would have inherited from their fathers. But this speculative explanation based on mother's status cannot be the sole one, because, if it were, we would observe a change over time in the extent to which measured educational attainment explained social mobility among women, which we did not. So the higher relative status of mothers - and their greater likelihood of being in the labour market at all - might have changed the ways in which they could influence their children's opportunities, rather than whether they did so.

$\mathbf{5 . 4}$ In two respects this analysis has perhaps supplemented conclusions reached by the wider comparative studies. The first concerns divergence. Although the absolute mobility of people born in Scotland and England may be converging, just as has been found in the 1990s wave of comparative mobility studies (Breen and Luijkx, 2004a), the same cannot be said of people born in Wales. This conclusion raises many questions answers to which would require different kinds of empirical study. Is the divergence of Wales related to its previous very heavy reliance on industrial and extractive employment, both of which have collapsed since the 1980s? We must bear in mind here, moreover, that our data measure the opportunities available to people from particular places, not the opportunities within them. Thus part of this different pattern has to do with different access to the most economically dynamic parts of the UK economy, mostly in the south-east of England. It may be that what we are observing here is an effect of what Fielding (1992) has called the 'escalator' role of that region: able people from other regions move there and gain promotion 
there. If the tendency to do so among younger cohorts was greater from Scotland than from Wales, then we would expect to see our patterns of convergence between Scotland and England but not between Wales and England. However, this cannot be the whole explanation, because the patterns we observed were also found when attention was confined to people who remained in their home country. Perhaps, then, the south-east of Scotland (around Edinburgh) is becoming, on a smaller scale, an escalator region in its own right. Whatever the explanation, our conclusions do point to the importance of continuing to compare societies which may have converged in the past. Not only does modernisation not entail convergence (as Marshall et al. (1997) argue), it does not preclude re-divergence.

5.5 The second conclusion arises from comparing mobility at current class with mobility at initial class. These analyses led to similar results, notably concerning the increase in downward mobility in recent cohorts and the growing divergence of Wales from Scotland and England; thus mobility within a career does not fundamentally alter the patterns of association between origins and destinations that we have found. Broadly speaking, also, education does not explain patterns of mobility at either initial class or current class. If, in Britain, education does not strongly mediate the association of origins and destinations, then it is perhaps not surprising that the initial pattern of that association - mostly just after people have left full-time education - did not tell us what will happen later in their lives. The dynamics of the differences among these three countries in mobility to current class, and of the changes in it over time, must derive, not mainly from initial experiences in the labour market, but from its subsequent effects on people's careers and from the ways in which it rewards characteristics not captured by formal credentials, some of them indeed built up during careers themselves. This reminds us that class position - especially perhaps initial class position - may be as much about potential as about actual relative advantage, a point argued by, for example, Gershuny (2002a,b), Breen (2004), Noble (2000), Pahl (1996[1989], p. 89) and Sørensen (1991). For aggregates of people, then, the patterns of association between origins and initial class are not any more valid as an indicator of transmission than are the patterns between origins and current class, even though the latter is inevitably taken at arbitrary points in individuals' lives. Investigating current class, which most studies of social mobility are constrained to do, remains, for this reason, important.

5.6 The conclusions about the unchanging patterns of relative mobility ought to give pause to those policy makers who are currently trying to expand social mobility. As described in the research cited earlier, it seems difficult to bring about an increase in fluidity by political means. Equally unpalatable politically might be the further point that, at a time when the size of the service class as a destination is not growing as fast as the size of that class as an origin, any increase in fluidity would have to be accompanied by an increase in downward mobility by the children of the advantaged classes. There are then two conclusions from our analysis relevant to these political concerns. One is that increasing absolute upward mobility might be feasible and politically attractive whether or not fluidity changes, but that the only way in which policy could bring this about would be by promoting the further growth of the service class.

5.7 The other political conclusion would be that a necessary condition for an increase in fluidity without an increase in downward mobility by the already advantaged would be significant amounts of immigration from outside Britain to fill the lowest-level jobs. That is precisely what has been happening in recent years from central and eastern Europe. Nevertheless, even that is not straightforward, as Platt (2005) has shown from her analysis of the experience of social mobility among various ethnic groups in England and Wales (the number of which in the BHPS was too small for us to analyse reliably -62 born in England, 1 in Wales and 8 in Scotland). She found that white people who were born in Britain had lower levels of upward mobility than people of Indian, Chinese, Caribbean or white immigrant origins, who had used education to gain access to good-quality occupations (a point confirmed by our own analysis of the experience of Catholics predominantly of Irish origin - in Scotland (Paterson and lannelli, 2006)). The lowest levels of upward mobility were among people of Pakistani or Bangladeshi origin (for whom education did not seem to offer these opportunities). So Platt's research shows that, even if immigrants might temporarily fill the menial jobs that allow others to be upwardly mobile, one wave of immigration in itself could not permanently solve the problem of the slowing down of the expansion of the service class, because, in most (though not all) immigrant groups, the children will enter into the same competition for good jobs as the children of natives.

5.8 Our final pair of conclusions is methodological. The first of these is that migration within the UK did not seem to make any important difference to our results: we would have reached the same conclusions by restricting attention to those who were living in the country in which they were born as we have by including those who have moved around Britain. That is encouraging for analysis of surveys confined to one of the three countries, because it suggests that losing track of migrants would not distort the results.

5.9 The second methodological conclusion is that the comparative study of social mobility can find interesting topics to investigate at social levels lower than that of the state. The theories which are usually put forward to explain comparisons among state-defined territories tend, on the whole, to make no reference to states as such: they are theories such as modernisation or post-industrialism. To be truly general, such theories have to be able to explain sub-state comparisons as well. They work here for the comparison of Scotland with England, but the Welsh partial divergence suggests that these theories do not apply without modification.

\section{Appendix : The British Household Panel Study}

The data are from the first nine sweeps of the British Household Panel Study, 1991-1999. The BHPS was inaugurated in 1991 primarily - as the name implies - to track individuals' experience over time; it is funded by the ESRC and is carried out by the Institute for Social and Economic Research at Essex University. A rich set of information was collected in the first few waves of the survey on respondents' earlier lives, including date and country of birth, and the work which the respondents' parents were doing when the respondent was aged 14 (from which social class schemes may be derived). These baseline data 
were also then collected in 1999 from enhanced samples in Scotland and Wales. The objective of the original survey was to have 5,000 households throughout the UK, and thus about 10,000 adults (aged at least 16, although a few 15-year-olds appear in the data set), adding in all new adult members of households which these members subsequently formed; the sample was selected from the Postcode Address File, with households selected randomly within addresses. The 1999 enhancements augmented the Scottish and Welsh samples to about 1,500 households each, yielding total samples sizes in these countries of around 3,000 adults (including the surviving members from the original sample); there are approximately 9,000 sample members in England. The new sample included full representation of the area north and west of the Great Glen in Scotland, although the original sample did not. The present analysis uses only those sample members from the earlier waves who were still in the study at wave nine. Weights are used to compensate for non-response, and - when analysing data from the whole of Britain - to compensate for what is now the over-sampling of Scotland and Wales. Because people who have not answered a particular question at one wave may be asked it again at a later wave, and because some information (such as current employment) is up-dated at each wave, the data set used here has been collated by matching all of the first nine waves. Further information is available from the survey's web site, at http://www.iser.essex.ac.uk/bhps/index.php.

\section{Tables}

Table 1

Distribution of origins and destinations, by country of birth, among people aged 23-62 in 1999

\begin{tabular}{|c|c|c|c|c|c|c|}
\hline \multirow[t]{2}{*}{ Cass } & \multicolumn{2}{|c|}{ bom in England } & \multicolumn{2}{|c|}{ bom in Wales } & \multicolumn{2}{|c|}{ bom in Scotland } \\
\hline & orizin & destination & orizin & destination & orizin & destination \\
\hline Higher grade professional (I) & 15.1 & 18.2 & 13.2 & 20.5 & 16.0 & 17.1 \\
\hline Lower grade professional (II) & 14.4 & 22.0 & 15.5 & 17.3 & 11.1 & 22.3 \\
\hline Routine non-manual (III a,b) & 17.0 & 21.0 & 14.1 & 17.5 & 18.1 & 22.3 \\
\hline Self-employed (IVa,b,c) & 11.8 & 9.2 & 11.4 & 9.9 & 11.1 & 7.2 \\
\hline Skilled manual (V,VI) & 24.5 & 13.9 & 23.8 & 16.4 & 24.8 & 14.6 \\
\hline Unskilled manual (VIIa,b) & 17.1 & 15.6 & 22.0 & 18.4 & 18.9 & 16.5 \\
\hline $\begin{array}{l}\text { Dissimilarity index comparing } \\
\text { origins and destinations }\end{array}$ & \multicolumn{2}{|c|}{15} & \multicolumn{2}{|c|}{13} & \multicolumn{2}{|c|}{17} \\
\hline Sample size & \multicolumn{2}{|c|}{4754} & \multicolumn{2}{|c|}{1053} & \multicolumn{2}{|c|}{1523} \\
\hline
\end{tabular}

Origin class defined by dominance rule (i.e. the higher of the status of father and mother when respondent aged 14); destination class defined by respondent's current class or, when that was not available, by the highest-class person in the respondent's household. Omits others. Categories of Goldthorpe scheme contributing to each summary category are shown in brackets.

Weighted; sample sizes unweighted. 
Table 2

Dissimilarity index comparing countries of birth, by birth cohort

\begin{tabular}{|c|c|c|c|}
\hline \multicolumn{2}{|c|}{ bom in Wales } & \multicolumn{2}{|c|}{ borm in Scotland } \\
\hline $\begin{array}{l}\text { comparing } \\
\text { origins }\end{array}$ & $\begin{array}{l}\text { comparing } \\
\text { destinations } \\
\text { (current job) }\end{array}$ & $\begin{array}{l}\text { comparing } \\
\text { ongins }\end{array}$ & $\begin{array}{l}\text { comparing } \\
\text { destinations } \\
\text { (current iob) }\end{array}$ \\
\hline
\end{tabular}

bom in England:

$\begin{array}{lrrrr}\text { all } & 6 & 8 & 4 & 3 \\ \text { bom } 1937-46 & 15 & 13 & 11 & 12 \\ \text { bom } 1947-56 & 7 & 11 & 6 & 6 \\ \text { bom } 1957-66 & 8 & 6 & 6 & 6 \\ \text { bom } 1967-76 & 14 & 12 & 9 & 3\end{array}$

bom in Wales:

$\begin{array}{lrr}\text { all } & 8 & 10 \\ \text { bom 1937-46 } & 11 & 24 \\ \text { bom 1947-56 } & 9 & 13 \\ \text { bom 1957-66 } & 13 & 11 \\ \text { bom } 1967-76 & 16 & 13\end{array}$

Table 3

Social mobility, by country of birth, among people aged 23-62 in 1999

$\begin{array}{lccc}\text { mobility } & \text { bom in England } & \text { bom in Wales } & \text { bom in Scotland } \\ \text { downward } & 31.2 & 31.6 & 30.6 \\ \text { immobile } & 24.2 & 22.8 & 24.3 \\ \text { upward } & 44.5 & 45.6 & 45.1 \\ \text { Sample size } & 4754 & 1053 & 1523\end{array}$

Based on class categories shown in Table 1 .

Weighted; sample sizes unweighted. 
Table 4

Resuls of log-linear models of onigin class, current class and birthplace

\begin{tabular}{|c|c|c|c|}
\hline & Model & $\mathrm{df}$ & $\mathrm{L}^{2}$ \\
\hline 1 & $\mathrm{O}, \mathrm{D}, \mathrm{B}, \mathrm{OD}, \mathrm{OB}, \mathrm{DB}$ & 50 & 51.3 \\
\hline 2 & $\mathrm{O}, \mathrm{D}, \mathrm{B}, \mathrm{OD}, \mathrm{OB}$ & $\begin{array}{l}60 \\
(-50)\end{array}$ & $\begin{array}{l}89.0^{*} \\
(-69.9)^{*}\end{array}$ \\
\hline 3 & $\mathrm{O}, \mathrm{D}, \mathrm{B}, \mathrm{OD}, \mathrm{OB}, \mathrm{ODB}$ & 10 & $19.1^{*}$ \\
\hline
\end{tabular}

Unweighted data. An asterisk indicates p-value less than 0.05 .

$d f=$ residual degrees of freedom.

$O=$ origin class (Goldthorpe with 6 categories).

$D=$ current class (Goldthorpe with 6 categories).

$B=$ birthplace (England, Wales, Scotiand).

Table 5

Distribution of origins and destinations, by birth cohort and country of birth, among people aged 23-62 in 1999

Cass bom in England

\begin{tabular}{|c|c|c|c|c|c|c|c|c|}
\hline \multirow[t]{2}{*}{ birth cohort } & \multicolumn{2}{|c|}{$1937-46$} & \multicolumn{2}{|c|}{$1947-56$} & \multicolumn{2}{|c|}{$1957-66$} & \multicolumn{2}{|c|}{$1967-76$} \\
\hline & origin & dest'n & origin & dest'n & origin & dest'n & origin & dest'n \\
\hline Higher grade professional & 88 & 16.7 & 11.4 & 18.0 & 18.7 & 20.5 & 20.0 & 16.6 \\
\hline Lower grade professiomal & 11.2 & 19.6 & 14.7 & 20.6 & 14.0 & 22.9 & 17.5 & 24.4 \\
\hline Routme nom-marwal & 10.2 & 21.2 & 16.7 & 22.1 & 18.8 & 19.9 & 20.7 & 21.1 \\
\hline Self-enqbyed & 12.0 & 11.3 & 10.7 & 96 & 11.6 & 99 & 13.2 & 62 \\
\hline Skilled & 33.3 & 12.9 & 27.1 & 14.2 & 21.7 & 12.4 & 17.8 & 16.6 \\
\hline Unskilled & 24.5 & 18.3 & 19.3 & 15.5 & 15.2 & 14.4 & 10.9 & 15.1 \\
\hline $\begin{array}{l}\text { Dissimilarity index } \\
\text { comparmz onizins and } \\
\text { destimations }\end{array}$ & \multicolumn{2}{|c|}{27} & \multicolumn{2}{|c|}{18} & \multicolumn{2}{|c|}{12} & \multicolumn{2}{|c|}{12} \\
\hline \multirow[t]{2}{*}{ Sample six } & \multicolumn{2}{|c|}{806} & \multicolumn{2}{|c|}{1216} & \multicolumn{2}{|c|}{1492} & \multicolumn{2}{|c|}{1250} \\
\hline & \multicolumn{8}{|c|}{ borm in Wales } \\
\hline \multirow[t]{2}{*}{ birth cohort } & \multicolumn{2}{|c|}{$1937-46$} & \multicolumn{2}{|c|}{$1947-56$} & \multicolumn{2}{|c|}{$1957-66$} & \multicolumn{2}{|c|}{$1967-76$} \\
\hline & origin & dest'n & origin & dest'n & origin & dest'n & origin & dest'n \\
\hline Higher grade professiomal & 12.3 & 17.2 & 86 & 22.1 & 20.0 & 22.9 & 10.8 & 17.6 \\
\hline Lower grade professional & 15.8 & 19.0 & 16.2 & 14.4 & 16.2 & 19.0 & 13.5 & 17.6 \\
\hline Routine non-manual & 35 & 13.8 & 18.1 & 17.3 & 11.4 & 19.0 & 20.3 & 17.6 \\
\hline Self-errybyed & 14.0 & 17.2 & 86 & 96 & 11.4 & 10.5 & 13.5 & 4.1 \\
\hline Skilled & 24.6 & 19.0 & 24.8 & 15.4 & 21.9 & 11.4 & 24.3 & 21.6 \\
\hline Unshilled & 29.8 & 13.8 & 23.8 & 21.2 & 19.0 & 17.1 & 17.6 & 21.6 \\
\hline $\begin{array}{l}\text { Dissimilanty index } \\
\text { comparmz onigins and } \\
\text { destmations }\end{array}$ & \multicolumn{2}{|c|}{22} & \multicolumn{2}{|c|}{15} & \multicolumn{2}{|c|}{13} & \multicolumn{2}{|c|}{15} \\
\hline Sample size & \multicolumn{2}{|c|}{177} & \multicolumn{2}{|c|}{296} & \multicolumn{2}{|c|}{328} & \multicolumn{2}{|c|}{252} \\
\hline
\end{tabular}




\begin{tabular}{|c|c|c|c|c|c|c|c|c|}
\hline \multirow{3}{*}{ birth cohort } & \multicolumn{8}{|c|}{ bom in Scotland } \\
\hline & \multicolumn{2}{|c|}{$1937-46$} & \multicolumn{2}{|c|}{$1947-56$} & \multicolumn{2}{|c|}{$1957-66$} & \multicolumn{2}{|c|}{$1967-76$} \\
\hline & orizin & dest'n & origin & dest'n & origin & dest'n & orizin & dest'n \\
\hline Higher grade professiomal & 98 & 13.7 & 12.8 & 20.7 & 16.4 & 16.4 & 23.7 & 15.8 \\
\hline Lower grade professiomal & 76 & 16.0 & 10.1 & 23.4 & 11.9 & 22.8 & 13.9 & 25.1 \\
\hline Routine nom-marual & 11.4 & 24.4 & 16.0 & 21.3 & 19.6 & 21.5 & 23.1 & 23.4 \\
\hline Self-ermbyed & 15.2 & 92 & 10.6 & 69 & 11.9 & 82 & 75 & 4.1 \\
\hline Skilled & 25.8 & 99 & 27.7 & 13.8 & 26.5 & 16.4 & 19.1 & 17.0 \\
\hline Unshilled & 30.3 & 26.7 & 22.9 & 13.8 & 13.7 & 14.6 & 12.7 & 14.6 \\
\hline $\begin{array}{l}\text { Dissimilarity index } \\
\text { comparmz onizins and } \\
\text { destimations }\end{array}$ & \multicolumn{2}{|c|}{25} & \multicolumn{2}{|c|}{27} & \multicolumn{2}{|c|}{14} & \multicolumn{2}{|c|}{13} \\
\hline Sample sire & \multicolumn{2}{|c|}{221} & \multicolumn{2}{|c|}{390} & \multicolumn{2}{|c|}{503} & \multicolumn{2}{|c|}{400} \\
\hline \multicolumn{9}{|l|}{ Cass definitions as in Table 1 . } \\
\hline \multicolumn{9}{|c|}{ Weighted: sanple sizes unweighted. } \\
\hline
\end{tabular}

Table 6

Social mobility, by birth cohort and country of birth, among people aged 23-62 in 1999

Mobuilty

birth cohort

193746

24.5

23.7

51.9

806

Sample sias

193746

birth cohort

9374

downward

immobile

29.8

21.1

49.1

177

Sample sire

downward

birth cohort

$1937-46$

immobile

27.6

26.1

46.3

221

Sample sire

Based on class categories shown in Table 5 .

Weighted; sarple sizes unweighted. 
Table T

Results of log-linear models of origin class, current class, birthplace and birth cohort

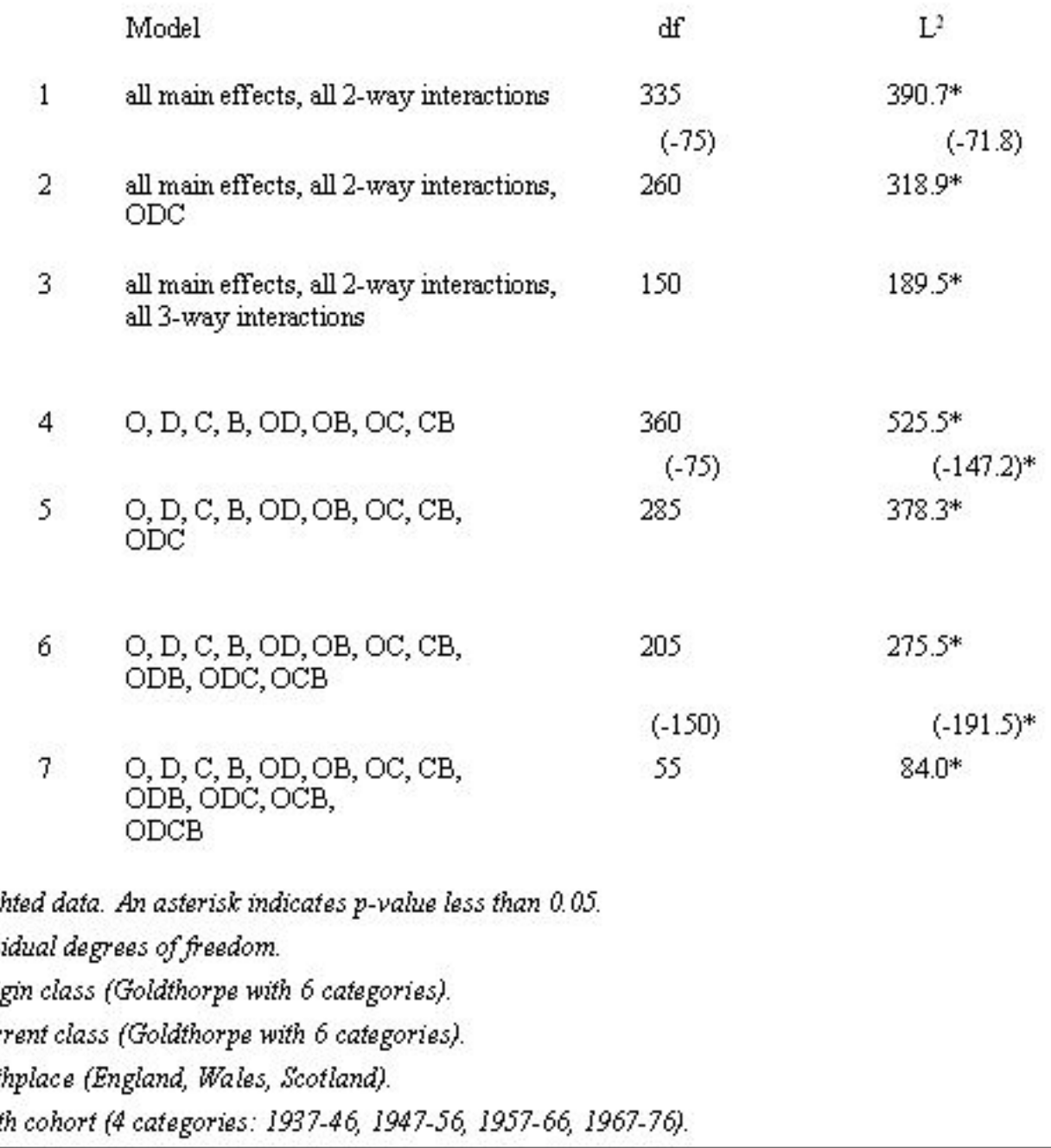


Table 8

Upward mobility by educational attainment and birth cohort, among people aged 23-62 in 1999

\begin{tabular}{|c|c|c|c|c|c|c|c|c|}
\hline \multirow[b]{2}{*}{$\begin{array}{l}\% \text { who have been } \\
\text { upwardly mobile at } \\
\text { current class }\end{array}$} & \multicolumn{8}{|c|}{ birth cohort } \\
\hline & \multicolumn{2}{|c|}{$1937-46$} & \multicolumn{2}{|c|}{$1947-56$} & \multicolumn{2}{|c|}{$1957-66$} & \multicolumn{2}{|c|}{$1967-76$} \\
\hline $\begin{array}{l}\text { Lower than lower } \\
\text { secondary education }\end{array}$ & 48.0 & & 40.0 & & 36.2 & & 38.7 & \\
\hline sample size & & 508 & & 571 & & 454 & & 224 \\
\hline $\begin{array}{l}\text { Lower secondary } \\
\text { education }\end{array}$ & 55.5 & & 50.8 & & 46.2 & & 33.5 & \\
\hline sample size & & 201 & & 324 & & 554 & & 424 \\
\hline $\begin{array}{l}\text { Upper secondary } \\
\text { education }\end{array}$ & 41.4 & & 54.0 & & 42.5 & & 34.1 & \\
\hline sample size & & 88 & & 203 & & 294 & & 330 \\
\hline $\begin{array}{l}\text { Higher education } \\
\text { below degree }\end{array}$ & 54.3 & & 53.0 & & 44.2 & & 38.1 & \\
\hline sample size & & 293 & & 535 & & 620 & & 527 \\
\hline \multirow[t]{2}{*}{ Degree } & 55.8 & & 56.1 & & 43.2 & & 34.9 & \\
\hline & & 85 & & $23 \mathrm{I}$ & & 361 & & 372 \\
\hline \multicolumn{9}{|c|}{ Weighted; sample sizes unweighted. } \\
\hline \multicolumn{9}{|c|}{ Combines those born in England, Wales and Scotand. } \\
\hline
\end{tabular}

Table 9

Distribution of origins and first job after leaving full-time education, by country of birth, among people aged 23-62 in 1999

\begin{tabular}{|c|c|c|c|c|c|c|}
\hline \multirow[t]{2}{*}{ Cass } & \multicolumn{2}{|c|}{ bom in England } & \multicolumn{2}{|c|}{ bom in Wales } & \multicolumn{2}{|c|}{ born in Scotland } \\
\hline & orizin & destination & origin & destination & origin & destimation \\
\hline Higher grade professional (I) & 13.7 & 3.8 & 11.8 & 3.9 & 13.5 & 4.1 \\
\hline Lower grade professional (II) & 14.0 & 10.4 & 14.4 & 9.7 & 10.9 & 10.5 \\
\hline Routine non-manual (IIIa,b) & 16.4 & 39.5 & 13.4 & 33.8 & 16.3 & 36.9 \\
\hline Self-employed (IVa,b,c) & 12.0 & 1.0 & 11.0 & 1.3 & 10.8 & 1.1 \\
\hline Skilled (V,VI) & 25.3 & 22.3 & 25.5 & 20.9 & 26.8 & 22.7 \\
\hline Unskilled (VIIa,b) & 18.7 & 22.9 & 23.9 & 30.4 & 21.6 & 24.7 \\
\hline $\begin{array}{l}\text { Dissimilarity index comparing } \\
\text { origins and destinations }\end{array}$ & \multicolumn{2}{|c|}{27} & \multicolumn{2}{|c|}{27} & \multicolumn{2}{|r|}{24} \\
\hline Sample size & \multicolumn{2}{|c|}{4501} & \multicolumn{2}{|c|}{1218} & \multicolumn{2}{|c|}{1649} \\
\hline
\end{tabular}

Origin class defined by dominance rule (see Table 1). Omits those with no information on origin class or initial class. Weighted; sample sizes unweighted. 
Table 10

Dissimilarity index comparing countries of birth, by birth cohort

\begin{tabular}{cccc}
\multicolumn{2}{c}{ bom in Wales } & \multicolumn{2}{c}{ bom in Scotland } \\
comparing & comparing & comparing & comparing \\
origins & $\begin{array}{c}\text { destinations } \\
\text { (first job) }\end{array}$ & origins & destinations \\
& (first job)
\end{tabular}

bom in England:

$\begin{array}{lrrrr}\text { all } & 6 & 8 & 5 & 3 \\ \text { born } 1937-46 & 10 & 12 & 8 & 5 \\ \text { bom } 1947-56 & 7 & 5 & 6 & 6 \\ \text { bom } 1957-66 & 10 & 10 & 5 & 6 \\ \text { bom } 1967-76 & 12 & 14 & 9 & 6\end{array}$

bom in Wales:

all

$6 \quad 6$

bom 1937-46

$7 \quad 13$

bom $1947-56$

9

bom 1957-66

1110

bom 1967-76

12

sources: Tables 9 and 13 .

Table 11

Social mobility at first job after leaving full-time education, by country of birth, among people aged 23-62 in 1999

$\begin{array}{lccc}\text { mobility } & \text { bom in England } & \text { bom in Wales } & \text { bom in Scotland } \\ \text { downward } & 41.8 & 43.6 & 39.3 \\ \text { immobile } & 25.5 & 25.5 & 26.5 \\ \text { upward } & 32.6 & 31.0 & 34.2 \\ \text { Sample size } & 4501 & 1218 & 1649\end{array}$

Based on class categories shown in Table 9.

Weighted; sample sizes unweighted. 
Table 12

Results of log-linear models of origin class, initial class and birthplace

\begin{tabular}{|c|c|c|c|}
\hline & Model & $d f$ & $\mathrm{~L}^{2}$ \\
\hline 1 & $\mathrm{O}, \mathrm{D}_{1}, \mathrm{~B}, \mathrm{OD}_{1}, \mathrm{OB}, \mathrm{D}_{1} \mathrm{~B}$ & 50 & 66.0 \\
\hline & $\mathrm{O}, \mathrm{D}_{1}, \mathrm{~B}, \mathrm{OD}_{1}, \mathrm{OB}$ & $\begin{array}{l}60 \\
(-50)\end{array}$ & $\begin{array}{l}99.6^{*} \\
(-78.0)^{*}\end{array}$ \\
\hline & $\mathrm{O}, \mathrm{D}_{1}, \mathrm{~B}, \mathrm{OD}, \mathrm{OB}, \mathrm{OD}_{1} \mathrm{~B}$ & 10 & $21.6^{*}$ \\
\hline
\end{tabular}

Unweighted data. An asterisk indicates p-value less than 0.05 .

$d f=$ residual degrees of freedom.

$O=$ origin class (Goldthorpe with 6 categories).

$D_{1}=$ initial class (Goldthorpe with 6 categories).

$B=$ birthplace (England, Wales, Scotland).

Table 13

Distribution of origins and first job after leaving full-time education, by birth cohort and country of birth, among people aged 23-62 in 1999

\begin{tabular}{|c|c|c|c|c|c|c|c|c|}
\hline \multirow{3}{*}{ birth cohort } & \multicolumn{8}{|c|}{ bom in England } \\
\hline & \multicolumn{2}{|c|}{193746} & \multicolumn{2}{|c|}{$1947-56$} & \multicolumn{2}{|c|}{$1957-66$} & \multicolumn{2}{|c|}{$1967-76$} \\
\hline & orizin & dest'n & orizin & dest'n & origin & dest'n & orizin & dest'n \\
\hline Higher grade professional & 92 & 3.7 & 11.0 & 40 & 17.5 & 48 & 17.7 & 2.1 \\
\hline Lower grade professional & 10.4 & 78 & 14.2 & 13.3 & 14.6 & 11.1 & 17.8 & 8.1 \\
\hline Routme nom-marnal & 99 & 41.2 & 169 & 41.2 & 19.2 & 38.2 & 19.6 & 36.8 \\
\hline Self-ermbyed & 12.5 & 0.4 & 10.8 & 0.4 & 11.1 & 13 & 14.7 & 23 \\
\hline Skilled & 32.5 & 24.3 & 26.6 & 21.1 & 22.0 & 20.0 & 18.8 & 25.5 \\
\hline Unskilled & 25.5 & 22.6 & 20.6 & 20.0 & 15.7 & 24.4 & 11.4 & 25.3 \\
\hline $\begin{array}{l}\text { Dissimilarity index } \\
\text { comparme onigins and } \\
\text { destimations }\end{array}$ & \multicolumn{2}{|c|}{31} & \multicolumn{2}{|c|}{24} & \multicolumn{2}{|c|}{28} & \multicolumn{2}{|c|}{38} \\
\hline \multirow[t]{2}{*}{ Sample six } & \multicolumn{2}{|c|}{956} & \multicolumn{2}{|c|}{1203} & \multicolumn{2}{|c|}{1412} & \multicolumn{2}{|c|}{930} \\
\hline & \multicolumn{8}{|c|}{ bom in Wales } \\
\hline \multirow[t]{2}{*}{ birth cohort } & \multicolumn{2}{|c|}{$1937-46$} & \multicolumn{2}{|c|}{$1947-56$} & \multicolumn{2}{|c|}{$1957-66$} & \multicolumn{2}{|c|}{$1967-76$} \\
\hline & origin & dest'n & orizin & dest'n & origin & dest'n & origin & dest'n \\
\hline Higher grade professiomal & 12.0 & 3.7 & 78 & 6.1 & 15.6 & 09 & 12.2 & 55 \\
\hline Lower grade professional & 10.8 & 6.1 & 17.2 & 13.0 & 15.6 & 9.1 & 12.2 & 82 \\
\hline Routine nom-marnal & 60 & 31.7 & 17.2 & 37.4 & 11.0 & 34.5 & 189 & 28.8 \\
\hline Self-ermbyed & 10.8 & 12 & 78 & 00 & 12.8 & 18 & 14.9 & 2.7 \\
\hline Skilled & 27.7 & 23.2 & 25.9 & 20.9 & 23.9 & 20.9 & 24.3 & 19.2 \\
\hline Unskilled & 32.5 & 34.1 & 24.1 & 22.6 & 21.1 & 32.7 & 17.6 & 35.6 \\
\hline $\begin{array}{l}\text { Dissimilarity index } \\
\text { comparme onigins and } \\
\text { destimations }\end{array}$ & \multicolumn{2}{|c|}{27} & \multicolumn{2}{|c|}{20} & \multicolumn{2}{|c|}{35} & \multicolumn{2}{|c|}{28} \\
\hline Sample six & \multicolumn{2}{|c|}{277} & \multicolumn{2}{|c|}{336} & \multicolumn{2}{|c|}{348} & \multicolumn{2}{|c|}{257} \\
\hline
\end{tabular}




\begin{tabular}{|c|c|c|c|c|c|c|c|c|}
\hline \multirow{3}{*}{ birth cohort } & \multicolumn{8}{|c|}{ bom in Scotland } \\
\hline & \multicolumn{2}{|c|}{193746} & \multicolumn{2}{|c|}{$1947-56$} & \multicolumn{2}{|c|}{$1957-66$} & \multicolumn{2}{|c|}{$1967-76$} \\
\hline & origin & dest'n & origin & dest'n & origin & dest'n & origin & dest'n \\
\hline Higher grade professiomal & 10.6 & 28 & 11.7 & 40 & 15.2 & 49 & 17.2 & 52 \\
\hline Lower gade professional & 6.1 & 10.0 & 96 & 76 & 12.5 & 12.9 & 15.9 & 11.1 \\
\hline Routine nom-marmal & 83 & 40.6 & 15.7 & 41.4 & 18.8 & 32.0 & 22.5 & 33.3 \\
\hline Self-ermbyed & 12.8 & 1.1 & 10.2 & 10 & 11.6 & 13 & 86 & 13 \\
\hline Skilled & 30.6 & 20.6 & 27.4 & 23.2 & 26.8 & 22.7 & 21.2 & 24.8 \\
\hline Unskilled & 31.7 & 25.0 & 25.4 & 22.7 & 15.2 & 26.2 & 14.6 & 24.2 \\
\hline $\begin{array}{l}\text { Dissimilarity index } \\
\text { comparms onigins and } \\
\text { destimations }\end{array}$ & \multicolumn{2}{|c|}{36} & \multicolumn{2}{|c|}{26} & \multicolumn{2}{|c|}{25} & \multicolumn{2}{|c|}{24} \\
\hline Sample sixe & \multicolumn{2}{|c|}{322} & \multicolumn{2}{|c|}{426} & \multicolumn{2}{|c|}{518} & \multicolumn{2}{|c|}{383} \\
\hline
\end{tabular}

Table 14

Social mobility at first job after leaving full-time education, by birth cohort and country of birth, among people aged 23-62 in 1999

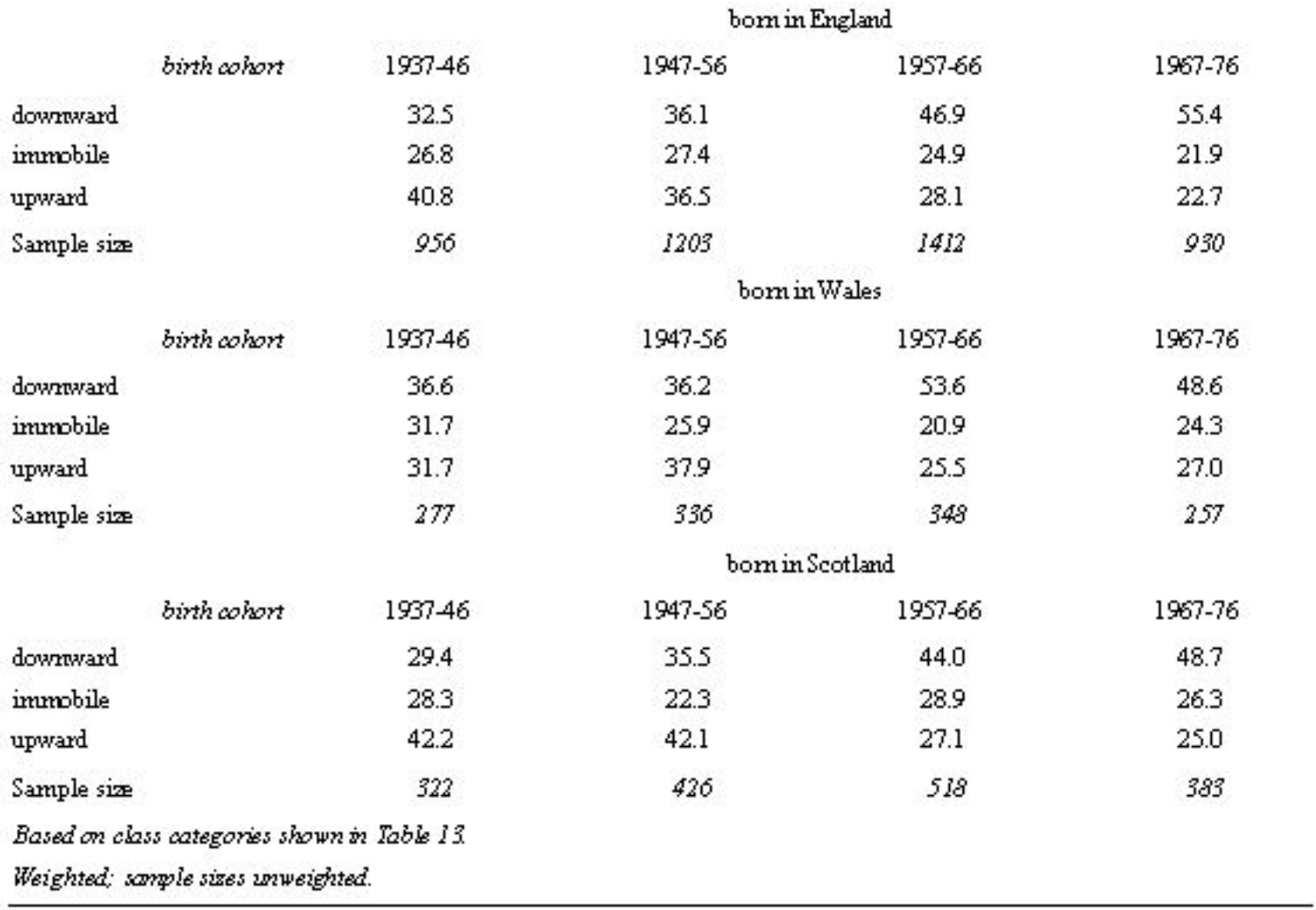


Table 15

\section{Results of log-linear models of origin class, initial class, birthplace and birth cohort}

\begin{tabular}{|c|c|c|c|}
\hline & Model & $\mathrm{df}$ & $\mathrm{L}^{2}$ \\
\hline 1 & all main effects, all 2-way interactions & $\begin{array}{l}335 \\
(-75)\end{array}$ & $\begin{array}{l}350.1 \\
(-89.5)\end{array}$ \\
\hline 2 & $\begin{array}{l}\text { all main effects, all 2-way interactions, } \\
O D_{1} \mathrm{C}\end{array}$ & 260 & 260.6 \\
\hline 3 & $\begin{array}{l}\text { all main effects, all 2-way interactions, } \\
\text { all 3-way interactions }\end{array}$ & 150 & 126.6 \\
\hline 4 & $\mathrm{O}, \mathrm{D}_{1}, \mathrm{C}, \mathrm{B}, \mathrm{OD}, \mathrm{OB}, \mathrm{OC}, \mathrm{CB}$ & $\begin{array}{l}360 \\
(-75)\end{array}$ & $\begin{array}{l}467.5^{*} \\
(-146.9)^{*}\end{array}$ \\
\hline 5 & $\begin{array}{l}\mathrm{O}, \mathrm{D}_{1}, \mathrm{C}, \mathrm{B}, \mathrm{OD}_{1}, \mathrm{OB}, \mathrm{OC}, \mathrm{CB} \text {, } \\
\mathrm{OD}_{1} \mathrm{C}\end{array}$ & 285 & 320.6 \\
\hline \multirow[t]{2}{*}{6} & $\begin{array}{l}\mathrm{O}, \mathrm{D}_{1}, \mathrm{C}, \mathrm{B}, \mathrm{OD}_{1}, \mathrm{OB}, \mathrm{OC}, \mathrm{CB}, \\
O \mathrm{D}_{1} \mathrm{~B}, \mathrm{OD}_{1} \mathrm{C}, \mathrm{OCB}\end{array}$ & 205 & 218.1 \\
\hline & & $(-150)$ & $(-143.7)$ \\
\hline 7 & $\begin{array}{l}\mathrm{O}, \mathrm{D}_{1}, \mathrm{C}, \mathrm{B}, O \mathrm{OD}_{1}, \mathrm{OB}, \mathrm{OC}, \mathrm{CB} \\
O \mathrm{D}_{1} \mathrm{~B}, O \mathrm{D}_{1} \mathrm{C}, \mathrm{OCB} \\
O D_{1} \mathrm{CB}\end{array}$ & 55 & $74.4^{*}$ \\
\hline
\end{tabular}

Unweighted data. An asterisk indicates p-value less than 0.05 .

$d f=$ residual degrees of freedom.

$O=$ origin class (Goldthorpe with 6 categories).

$D_{l}=$ initial class (Goldthorpe with 6 categories).

$B=$ birthplace (England, Wales, Scotiand).

$C=$ birth cohort (4 categories: 1937-46, 1947-56, 1957-66, 1967-76).

Table 16

Migration within the UK, by social mobility and birth cohort, among people aged 23-62 in 1999

\begin{tabular}{|c|c|c|c|c|c|}
\hline$\%$ not living in country & \multicolumn{4}{|c|}{ birth cohort } & \multirow[t]{2}{*}{ All } \\
\hline mobility $^{2}$ & $1937-46$ & $1947-56$ & $1957-66$ & $1967-76$ & \\
\hline downward & 10.4 & 8.2 & 7.2 & 4.7 & 7.2 \\
\hline imumobile & 6.2 & 4.5 & 6.7 & 4.4 & 5.4 \\
\hline upward & 5.6 & 78 & 6.3 & 4.9 & 6.3 \\
\hline All & 6.9 & 7.1 & 6.7 & 4.7 & 6.4 \\
\hline
\end{tabular}

'Restricted to people born in the UK 'Country' is defined as England, Wales, Scotland and Northern Ireland; by definition of the sample, all respondents are resident in the UK Place of residence is where respondent was living in 1999 .

Mobility is defined as for current class in the earlier tables.

Percentages are weighted. 


\section{References}

BLANE, D., Davey Smith, G. and Hart, C. (1999), 'Some social and physical correlates of intergenerational social mobility: evidence from the West of Scotland Collaborative Study', Sociology, 33, pp. 169-83.

BREEN, R. (2001), 'A Weberian approach to class analysis', in Wright, E. O. (ed.), Alternative Foundations of Class Analysis, University of Wisconsin, Madison, pp. 40-59.

BREEN, R. (2004), 'Social fluidity', working paper, Nuffield College, Oxford.

BREEN, R. and Luijkx, R. (2004a), 'Social mobility in Europe between 1970 and 2000', in Breen, R. (ed.), Social Mobility in Europe, Oxford: Oxford University Press, pp. 437-75.

BREEN, R. and Luijkx, R. (2004b), 'Conclusions', in Breen, R. (ed.), Social Mobility in Europe, Oxford: Oxford University Press, pp. 383-410.

BREEN, R. and Whelan, C. T. (1992), 'Explaining the Irish pattern of social fluidity: the role of the political', in Goldthorpe, J. H. and Whelan, C. T. (eds), The Development of Industrial Society in Ireland, Oxford: Oxford University Press, pp. 129-51.

BREEN, R. and Whelan, C. T. (1999), 'Social mobility in Ireland: a comparative analysis', in Heath, A. F., Breen, R. and Whelan, C. T. (eds), Ireland North and South: Perspectives from Social Science, Oxford: Oxford University Press and British Academy, pp. 319-39.

ERIKSON, R and Goldthorpe, J. H. (1992), The Constant Flux: A Study of Class Mobility in Industrial Societies, Oxford: Clarendon Press.

EVANS, G. (1992), Testing the validity of the Goldthorpe class schema', European Sociological Review, 8, pp. 211-32.

EVANS, G. and Mills, C. (2000), 'In search of the wage-labour/service contract: new evidence on the validity of the Goldthorpe class schema', British Journal of Sociology, 51, pp. 641-61.

FIELDING, A. J. (1992), 'Migration and social mobility: south east England as an escalator region', Regional Studies, 26, pp. 1-15.

GALLIE, D. (2000), 'The labour force', in Halsey, A. H. and J. Webb (eds), Twentieth-Century British Social Trends, London: Macmillan, pp. 281-323.

GERSHUNY, J. (2002a), 'A new measure of social position: social mobility and human capital in Britain', Working Papers of the Institute for Social and Economic Research, paper 2002-2, Colchester: University of Essex.

GERSHUNY, J. (2002b), 'Beating the odds (2): a new index of intergenerational social mobility', Working Papers of the Institute for Social and Economic Research, paper 2002-18, Colchester: University of Essex.

GOLDTHORPE, J. H. (1987), Social Mobility and Class Structure in Modern Britain, Oxford: Clarendon Press, second edition.

HALSEY, A. H. (1977), 'Towards meritocracy? The case of Britain', in Karabel, J. and Halsey, A. H. (eds), Power and Ideology in Education, Oxford: Oxford University Press, pp. 173-86.

HEATH A. and Payne, C. (1999), 'Twentieth century trend in social mobility in Britain', CREST (Centre for Research into Elections and Social Trends), working paper no.70.

HELLEVIK, O. (1997), 'Class inequality and egalitarian reform', Acta Sociologica, 40, pp. 377-98.

IANNELLI, C. and Paterson, L. (2007), 'Education and social mobility in Scotland', Research in Social Stratification and Mobility, Research in Social Stratification and Mobility, 25, pp219-32.

MARSHALL, G., Rose, D., Newby, H. and Vogler, C. (1988), Social Class in Modern Britain, London: Hutchinson.

MARSHALL, G. and Swift, A. (1993), 'Social class and social justice', British Journal of Sociology, 44, pp. 187-211.

MARSHALL, G. and Swift, A. (1999), 'On the meaning and measurement of inequality', Acta Sociologica, 1999, pp. 241-50.

MARSHALL, G., Swift, A. and Roberts, S. (1997), A gainst the Odds? Social Class and Social Justice in Industrial Societies, Oxford: Clarendon Press.

MCCRONE, D. (1992) Understanding Scotland: The Sociology of a Nation. London: Routledge.

NOBLE, T. (2000), 'The mobility transition: social mobility trends in the first half of the twenty-first century', Sociology, 34, pp. 35-51. 
PAHL, R. (1996 [1989]), 'Is the emperor naked? Some questions on the adequacy of sociological theory', in Lee, D. J. and Turner, B. S. (eds), Conflicts About Class, London: Longman, pp. 89-97 (abridged from International Journal of Urban and Regional Research, 13, pp. 109-20).

PARSONS, T. (1994), 'Equality and inequality in modern society, or social stratification revisited', in Grusky, D. (ed.), Social Stratification. Class, Race and Gender in Sociological Perspective, Boulder: Westview Press, p p.670-85.

PATERSON, L., lannelli, C., Bechhofer, F. and McCrone, D. (2004), 'Social class and social opportunity', ch. 6 in Paterson, L., Bechhofer, F. and McCrone, D., Living in Scotland, Edinburgh: Edinburgh University Press, pp. 80-104

PATERSON, L. and lannelli, C. (2006), 'Religion, social mobility and education in Scotland', British Journal of Sociology, 57, pp. 353-77.

PATERSON, L. and lannelli, C. (2007), 'Social class and educational attainment: a comparative study of England, Wales and Scotland', Sociology of Education, 80, pp 330-58. .

PAYNE, C., Payne, J. and Heath, A. (1994), 'Modelling trends in multi-way tables', in Dale, A. and Davies, R. B. (eds), Analysing Social and Political Change, London: Sage, pp. 43-74.

PAYNE, G. (1987), Employment and Opportunity, London: MacMillan Press.

PAYNE, G. and Roberts, J. (2002), 'Opening and closing the gates: recent developments in male social mobility in Britain', Sociological Research Online, 6. <http://www.socresonline.org.uk/6/4/payne.html>.

PLATT, L. (2005), Migration and Social Mobility, Bristol: Policy Press.

PRZEWORSKI, A. and Teune, H. (1970), The Logic of Comparative Social Inquiry, New York: Wiley.

RAFFE, D., Brannen, K., Croxford, L. and Martin, C. (1999), 'Comparing, England, Scotland, Wales and Northern Ireland; the case for "home internationals" in comparative research', Comparative Education, 35 , pp. 9-25.

RINGEN, S. (1997), Citizens, Families and Reform, Oxford: Clarendon.

SAUNDERS, P. (1995), 'Might Britain Be a Meritocracy', Sociology, 29, pp. 23-41.

SAVAGE, M. (2000), Class Analysis and Social Transformation, Buckingham: Open University Press.

SØRENSEN, A. B. (1991), 'On the usefulness of class analysis in research on social mobility and socioeconomic inequality', Acta Sociologica, 34, pp. 71-87.

SWIFT, A. (2000), 'Class analysis from a normative perspective', British Journal of Sociology, 51, pp. 66379.

SWIFT, A. and Marshall, G. (1997), 'Meritocratic equality of opportunity: economic efficiency, social justice, or both?', Policy Studies, 18, pp. 35-48.

VERMUNT, J. K., (1997), LEM: A General Program for the Analysis of Categorical Data, available from the web site of the University of Tilburg at http://www.tilburguniversity.nl/.

TREIMAN, D. J. (1970), 'Industrialisation and social stratification', in Laumann, E. O. (ed.) Social Stratification: Research and Theory for the 1970s, Indianapolis: Bobbs- Merrill, pp. 207-34.

WHELAN, C. T. (2004), 'Economic boom and social mobility: the Irish experience', working paper, Dublin: Economic and Social Research Institute. 